\title{
Association between epidermal growth factor receptor mutations and the expression of excision repair cross-complementing protein 1 and ribonucleotide reductase subunit M1 mRNA in patients with non-small cell lung cancer
}

\author{
CHUN-WEI XU ${ }^{1 *}$, GANG WANG $^{2 *}$, WU-LONG WANG ${ }^{3,4}$, WEN-BIN GAO $^{2}$, CHUAN-JUN HAN $^{3}$, JING-SHAN GAO $^{5}$, \\ YANG LI $^{6}$, LIN WANG ${ }^{7}$, LI-YING ZHANG ${ }^{1}$, YU-PING ZHANG ${ }^{8}$, YU-WANG TIAN ${ }^{1}$ and JIN-NV FANG ${ }^{9}$ \\ ${ }^{1}$ Department of Pathology, The General Military Hospital of Beijing PLA, Beijing 100700; ${ }^{2}$ Department of Oncology, \\ Affiliated Zhongshan Hospital of Dalian University, Dalian, Liaoning 116001; ${ }^{3}$ Graduate School of Dalian University, \\ Dalian, Liaoning 116622; ${ }^{4}$ The Second Affiliated Hospital of Baotou Medical College, Baotou, Inner Mongolia 014030; \\ ${ }^{5}$ Department of Clinical Medicine, Dalian Medical University, Dalian, Liaoning 116044; ${ }^{6}$ Department of Oncology, \\ The General Military Hospital of Beijing PLA, Beijing 100700; ${ }^{7}$ Department of Pathology, Shanxi Da Hospital, \\ Shanxi Academy of Medical Sciences, Taiyuan, Shanxi 030001; ${ }^{8}$ Department of Pathology, \\ The People's Hospital of Weifang, Weifang, Shandong 261041; ${ }^{9}$ Department of Medicine, \\ Yanbian University, Yanji, Jilin 133002, P.R. China
}

Received June 16, 2014; Accepted December 29, 2014

DOI: $10.3892 / \mathrm{etm} .2015 .2196$

\begin{abstract}
The present study aimed to investigate the association between epidermal growth factor receptor $(E G F R)$ gene mutations and excision repair cross-complementing protein 1 (ERCCl) and ribonucleotide reductase subunit M1 (RRMI) mRNA expression in non-small cell lung cancer (NSCLC) tissue. The quantitative polymerase chain reaction was used to detect EGFR mutations, and ERCCl and RRM1 mRNA expression in 257 cases of NSCLC. In the NSCLC samples the EGFR mutation rate was $49.03 \%$ (126/257). The rate was higher in females and non-smoking patients $(\mathrm{P}<0.05)$. High expression of ERCCl mRNA was observed in $47.47 \%$ of the samples (122/257), while a high $R R M 1$ mRNA expression was observed in $61.87 \%$ of the samples (159/257). In comparison with patients with NSCLC without $E G F R$ mutations, patients with $E G F R$ mutations had significantly lower levels of $E R C C 1$ mRNA expression $(\mathrm{P}<0.05)$; however, EGFR mutations and
\end{abstract}

Correspondence to: Professor Wen-Bin Gao, Department of Oncology, Affiliated Zhongshan Hospital of Dalian University, 6 Jiefang Street, Zhongshan, Dalian, Liaoning 116001, P.R. China E-mail: drwenbingao@163.com

*Contributed equally

Key words: non-small cell lung cancer, epidermal growth factor receptor, excision repair cross-complementing protein 1, ribonucleotide reductase subunit M1, molecular detection, individualized treatment expression levels of RRMI mRNA were not correlated in NSCLC tissues ( $\mathrm{P}>0.05)$. In addition, ERCC1 mRNA expression was not correlated with the expression levels of RRMI mRNA ( $\mathrm{P}>0.05)$. In conclusion, patients with NSCLC with $E G F R$ mutations tend to have a low expression of ERCCl mRNA and may potentially benefit from platinum-based chemotherapy.

\section{Introduction}

Globally, lung cancer has the highest rates of morbidity and mortality of all malignancies (1). Non-small cell lung cancer (NSCLC) accounts for 80-85\% of lung cancer cases worldwide (2).

Human epidermal growth factor receptor (EGFR) belongs to the type I receptor family. This family has four cognate family members, including EGFR (HER1), HER2, HER3 and HER4, which mediate the following signal transduction pathways: Ras-Raf-mitogen-activated protein kinase kinase-extracellular signal-regulated kinase-mitogen-activated protein kinase, phospholipase $\mathrm{C}-\gamma$, phosphatidylinositol-3-kinase/phosphoinositide-dependent kinase 1 and Janus kinase/signal transducers and activators of transcription (3). These receptors regulate cell proliferation, differentiation and apoptosis (4). $E G F R$ mutations in patients with NSCLC occur in the intracellular tyrosine kinase (TK) region above the first four exons (18 to 21). A total of 30 different types of mutations have been identified in the TK region (5), the most common occurring in exons 19 and 21, which account for $~ 85 \%$ of all the mutations (6).

Excision repair cross-complementing gene $1(E R C C l)$ is the key gene in two DNA repair pathways: nucleotide excision 
repair (NER) and chain crosslink repair (7). Overexpression of ERCCl can rapidly repair damaged DNA arrest at the $\mathrm{G}_{2} / \mathrm{M}$ phase and cause cells to be resistant to platinum (8). Ribonucleotide reductase subunit M1 (RRMI) is involved in DNA synthesis and repair (9). Results from the Iressa ${ }^{\circledR}$ Pan-Asia Study (10) clinical trial indicated that, in Asian populations, patients with EGFR mutations were more responsive to chemotherapy than patients with wild-type $E G F R$. Patients with lung cancer with low expression of ERCCI and RRMI are more responsive to gemcitabine- and platinum-based chemotherapy, respectively $(11,12)$. Patients with NSCLC are generally treated with chemotherapy drugs, including cisplatin and gemcitabine. In the present study, 257 patients with stages I-IV NSCLC from multiple hospitals were analyzed for the presence of EGFR mutations and expression levels of $E R C C l$ and $R R M 1 \mathrm{mRNA}$. The data were statistically analyzed to determine significant correlations between EGFR mutations and expression of these two chemotherapy resistance genes in patients with NSCLC. These data may prove useful in further identifying more effective individualized treatment plans for patients with $E G F R$ mutations, particularly for patients with small-molecule EGFR-tyrosine kinase inhibitor (EGFR-TKI) primary or secondary resistance.

\section{Materials and methods}

Specimens. For the detection of EGFR mutations, as well as $E R C C 1$ and $R R M 1$ mRNA expression levels, paraffin tissue specimens were collected from 257 patients from the General Military Hospital of Beijing PLA (Beijing, China; 103 cases), the Affiliated Zhongshan Hospital of Dalian University (Dalian, China; 58 cases) and the People's Hospital of Weifang (Weifang, China; 96 cases). The patients had undergone surgery between 2004 and 2013; the pathological diagnosis was adenocarcinoma, and patients had not received preoperative chemotherapy, radiotherapy or biological immunotherapy. All protocols in the present study were approved by the Human Clinical and Research Ethics Committees of the General Military Hospital of Beijing PLA, the Affiliated Zhongshan Hospital of Dalian University (Dalian, China) and the People's Hospital of Weifang (Weifang, China). Written informed consent was obtained from all of the patients.

Reagents and instruments. The DNA and RNA extraction kits were purchased from Qiagen (Hilden, Germany). The human EGFR mutation qualitative detection kit and the tumor-related gene expression relative quantification detection kit (ERCCI and $R R M 1$ ) were obtained from Amoy Diagnostics Co., Ltd. (Xiamen, China). The B-500 instrument to measure nucleic acid protein concentrations was purchased from Shanghai Chong Meng Biotechnology Co. Ltd. (Shanghai, China) and the ABI 7500 quantitative polymerase chain reaction (qPCR) instrument was purchased from Applied Biosystems ${ }^{\circledR}$ (Life Technologies, Foster City, CA, USA).

qPCR to detect EGFR mutations in NSCLC tissues. Between four and eight $4-\mu \mathrm{m}$-thick paraffin tissue sections were obtained and dewaxed. The genomic RNA extraction kit was used to extract RNA from the tissue samples according to the manufacturer's instructions. A spectrophotometer was used to determine the purity and concentration of the extracted RNA, which was used as a template to synthesize the corresponding DNA. The human EGFR mutation qualitative detection kit, which contains 29 different fusion mutant primers and probes to amplify EGFR exons 18, 19, 20 and 21, was used (ADx-EG09; Amoy Diagnostics Co., Ltd.); the DNA was amplified in an ABI 7500 qPCR instrument (Fig. 1A and B). The qPCR cycling conditions were set as follows: $95^{\circ} \mathrm{C}$ for $5 \mathrm{~min}$, follwed by 45 cycles of $95^{\circ} \mathrm{C}$ for $30 \mathrm{sec}, 60^{\circ} \mathrm{C}$ for $30 \mathrm{sec}$ and $72^{\circ} \mathrm{C}$ for $45 \mathrm{sec}$.

qPCR to detect the expression of ERCCI and RRMI mRNA in NSCLC tissue. RNA was extracted from $4-\mu \mathrm{m}$-thick paraffin tissue sections in accordance with the aforementioned methods. The tumor-associated gene expression detection kit for ERCCl (ADx-ER01) and RRM1 (ADx-RR01) (Amoy Diagnostics Co., Ltd.) was used to determine the mRNA expression level of these genes using the absolute quantitative method; $\beta$-actin was used as the reference gene. $E R C C l$ had a standard mean of $4.29 \times 10^{-3}$, and $R R M 1$ had a standard mean of $11.37 \times 10^{-3}$ (Fig. 1C).

Statistical analysis. The data were analyzed using the statistical software SPSS (version 19.0; IBM SPSS, Armonk, NY, USA) using the $\chi^{2}$ and Fisher's exact test with a test level $\alpha=0.05$. The $\mathrm{P}$-value was set to bilateral distribution and $\mathrm{P}<0.05$ was considered to indicate a statistically significant difference.

\section{Results}

Association between EGFR mutations, expression of ERCC1 and RRM1 $\mathrm{mRNA}$, and patient clinical characteristics. Of the 257 cases of NSCLC, EGFR mutations were present in 126 cases (49.03\%). The EGFR mutation rate was higher in non-smoking patients $(92 / 158,58.23 \%$; $\mathrm{P}<0.001)$; however, the EGFR mutation rate was not associated with the age, tumor size, lymph-node metastasis or clinical stage of the patient. High expression of ERCCl mRNA was observed in $122 / 257$ cases (47.47\%). ERCC1 mRNA expression levels were not associated with the gender, age, smoking status, tumor size, lymph-node metastasis or clinical stage of the patient. High expression of $R R M 1$ mRNA was observed in 159/257 cases (61.87\%). RRMI mRNA expression levels were not associated with the gender, age, smoking status, tumor size, lymph-node metastasis or clinical stage of the patient (Table I).

Association between EGFR mutations and expression levels of ERCC1 mRNA. Of the 126 patients with NSCLC with an $E G F R$ mutation, 79 (62.70\%) showed low expression of $E R C C l$. Of the 131 patients with NSCLC with the wild-type $E G F R$ gene, $56(42.75 \%)$ had low expression of ERCCI mRNA. These data indicate that patients with NSCLC with an EGFR mutation had significantly lower expression of ERCC1 mRNA $(\mathrm{P}<0.05)$ (Table II).

Association between EGFR mutations and the expression level of RRMI mRNA. Of the 126 patients with NSCLC with an EGFR gene mutation, 51 (40.48\%) had low expression of RRM1 mRNA, while 47 out of the 131 patients (35.88\%) 
Table I. Association between EGFR mutations, ERCC1 and RRM1 mRNA expression, and patient clinical characteristics.

\begin{tabular}{|c|c|c|c|c|c|c|c|c|c|}
\hline \multirow[b]{2}{*}{ Clinical features } & \multicolumn{2}{|c|}{$E G F R$} & \multirow[b]{2}{*}{ P-value } & \multicolumn{2}{|c|}{ ERCCl } & \multirow[b]{2}{*}{ P-value } & \multicolumn{2}{|c|}{$R R M 1$} & \multirow[b]{2}{*}{ P-value } \\
\hline & Mutant (n) & Wild-type (n) & & $\operatorname{High}(\mathrm{n})$ & Low (n) & & $\operatorname{High}(\mathrm{n})$ & Low (n) & \\
\hline Gender & & & $<0.001$ & & & 0.898 & & & 0.088 \\
\hline Male & 52 & 86 & & 65 & 73 & & 92 & 46 & \\
\hline Female & 74 & 45 & & 57 & 62 & & 67 & 52 & \\
\hline Age, years & & & 0.287 & & & 0.943 & & & 0.714 \\
\hline$\geq 59$ & 68 & 62 & & 62 & 68 & & 79 & 51 & \\
\hline$<59$ & 58 & 69 & & 60 & 67 & & 80 & 47 & \\
\hline Smoking history & & & $<0.001$ & & & 0.199 & & & 0.129 \\
\hline Yes & 34 & 65 & & 52 & 47 & & 67 & 32 & \\
\hline No & 92 & 66 & & 70 & 88 & & 92 & 66 & \\
\hline Tumor diameter, $\mathrm{cm}$ & & & 0.282 & & & 0.687 & & & 0.292 \\
\hline$\geq 5$ & 56 & 67 & & 60 & 63 & & 72 & 51 & \\
\hline$<5$ & 70 & 64 & & 62 & 72 & & 87 & 47 & \\
\hline Lymph node metastasis & & & 0.903 & & & 0.470 & & & 0.188 \\
\hline Yes & 51 & 54 & & 47 & 58 & & 70 & 35 & \\
\hline No & 75 & 77 & & 75 & 77 & & 89 & 63 & \\
\hline Clinical stage & & & 0.203 & & & 0.339 & & & 0.577 \\
\hline I & 50 & 42 & & 40 & 52 & & 59 & 33 & \\
\hline II+III+IV & 76 & 89 & & 82 & 83 & & 100 & 65 & \\
\hline
\end{tabular}

$E G F R$, epidermal growth factor receptor; $E R C C 1$, excision repair cross-complementing protein 1; RRM1, ribonucleotide reductase subunit M1.

A

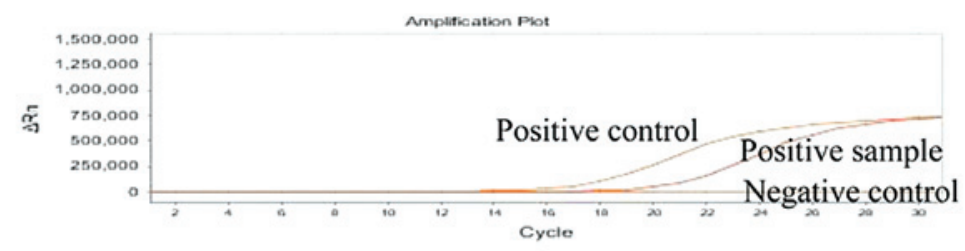

$\square \mathrm{A}=\mathrm{B} \square \mathrm{C} \square \mathrm{D} \square \mathrm{F} \square \mathrm{G} \square \mathrm{H}$

B

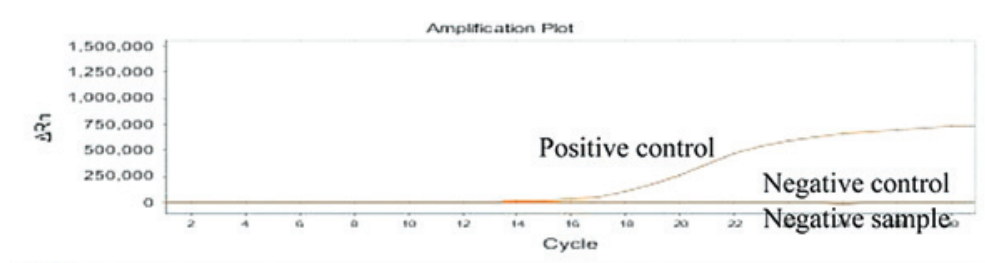

$\mathrm{A} \square \mathrm{B} \square \mathrm{C} \square \mathrm{D} \square \mathrm{E} \square \mathrm{F} \square \mathrm{G} \square \mathrm{H}$

C

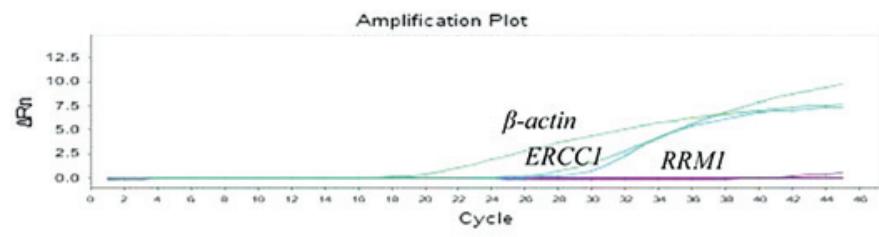

$\mathrm{A} \square \mathrm{B} \square \mathrm{C} \square \mathrm{D} \square \mathrm{E} \square \mathrm{F} \square \mathrm{H}$

Figure 1. Mutations of the EGFR gene and the expression of $E R C C 1$ and $R R M 1 \mathrm{mRNA}$. (A) Positive control, positive sample and negative control of the $E G F R$ gene. (B) Positive control, negative sample and negative control of the EGFR gene. (C) Expression of ERCC1 and RRM1 mRNA. EGFR, epidermal growth factor receptor; $E R C C 1$, excision repair cross-complementing protein 1; $R R M 1$, ribonucleotide reductase subunit $M 1$. 
Table II. Association between EGFR mutations and the expression level of ERCCI mRNA.

\begin{tabular}{lccc}
\hline & \multicolumn{2}{c}{ ERCC1 mRNA expression } & \\
\cline { 2 - 3 } EGFR & High (n) & Low (n) & Total (n) \\
\hline Mutant & 47 & 79 & 126 \\
Wild-type & 75 & 56 & 131 \\
Total (n) & 122 & 135 & 257 \\
\hline
\end{tabular}

$E G F R$, epidermal growth factor receptor; ERCC1, excision repair cross-complementing protein 1.

Table III. Association between EGFR mutations and the expression level of $R R M 1 \mathrm{mRNA}$.

\begin{tabular}{lccc}
\hline & \multicolumn{2}{c}{ RRM1 mRNA expression } & \\
\cline { 2 - 3 } EGFR & High (n) & Low (n) & Total (n) \\
\hline Mutant & 75 & 51 & 126 \\
Wild-type & 84 & 47 & 131 \\
Total (n) & 159 & 98 & 257 \\
\hline
\end{tabular}

$E G F R$, epidermal growth factor receptor; $R R M 1$, ribonucleotide reductase subunit M1.

Table IV. Association between the expression levels of ERCCI and RRM1 mRNA.

\begin{tabular}{lccc}
\hline \multirow{2}{*}{$\begin{array}{l}\text { ERCC1 mRNA } \\
\text { expression }\end{array}$} & \multicolumn{2}{c}{ RRM1 mRNA expression } & \\
\cline { 2 - 3 } & High (n) & Low (n) & Total (n) \\
\hline High & 72 & 50 & 122 \\
Low & 87 & 48 & 135 \\
Total (n) & 159 & 98 & 257 \\
\hline
\end{tabular}

$E R C C 1$, excision repair cross-complementing protein 1 ; $R R M 1$, ribonucleotide reductase subunit M1.

with the wild-type EGFR gene had low expression of RRM1 mRNA. These data indicate that there was no correlation between EGFR and RRMI mutations in patients with NSCLC (P>0.05) (Table III).

Association between the expression levels of ERCC1 and RRM1 mRNA. Of the 122 patients with NSCLC with high expression of ERCC1 mRNA, 72 cases (59.02\%) had high expression of $R R M 1$ mRNA. Of the 135 patients with NSCLC with low expression of ERCC1 mRNA, 48 cases (35.56\%) had low expression of $R R M 1$ mRNA. A total of 120 cases had low or high expression of both ERCCl and RRM1 mRNA, and 137 cases had contrasting expression levels of ERCCl and RRMI mRNA. These data indicate that the expression of ERCCI and RRMI mRNA was not significantly correlated $\left(\chi^{2}=0.800, P=0.371\right)$ in NSCLC tissue (Table IV).

\section{Discussion}

EGFR mutations and the responsiveness of NSCLC to the molecular targeted drugs gefitinib (trade name, Iressa) and erlotinib (trade name, Tarceva ${ }^{\circledR}$ ) have a close association $(13,14)$. Small-molecule TKIs have been shown to have a high efficiency in patients with an exon 19 deletion in the EGFR gene (15); however, patients with NSCLC with EGFR mutations in exon 20 are resistant to drug treatment with TKIs (16). Other studies have reported that the NER complexes prognosis is good but not suitable for receiving platinum-based chemotherapy $(17,18)$.

The results of the present study showed that the EGFR mutation rate was $48.03 \%(126 / 257)$ in patients with stages I-IV NSCLC, which is consistent with previously reported data $(14,19)$. A higher percentage of patients with NSCLC $(47.47 \%$; 122/257) showed high mRNA expression levels of ERCCl compared with data from a previous study (20), while the percentage of patients with NSCLC with a high RRM1 mRNA expression level $(61.87 \% ; 159 / 257)$ was consistent with data presented in a previous study (21). The expression levels of ERCCl and RRM1 mRNA were not associated with the gender, age, smoking status, tumor size, lymph node metastasis, pathological staging or other clinical characteristics of the patient.

The current study found that the mutational status of EGFR was associated with ERCC1 mRNA expression levels in patients with NSCLC; patients with EGFR mutations had a significantly lower expression of ERCC1 mRNA $(\mathrm{P}<0.05)$. EGFR mutations did not, however, significantly correlate with $R R M 1$ expression levels $(\mathrm{P}>0.05)$ in patients with NSCLC. A previous study has shown that EGFR mutations in patients with NSCLC were correlated with expression levels of ERCC1 ( $\mathrm{P}<0.001)$. Furthermore, EGFR mutations in the adenocarcinoma subgroup were correlated with ERCC1 expression levels $(\mathrm{P}=0.001)(22)$. It has also been shown that NER enzymes in cells can lead to cell damage, resulting in genomic instability and an increased mutation rate (23). Cancer cells with low expression of ERCCl have a decreased ability to repair DNA damage, an increase in the number of EGFR mutations and increased sensitivity to platinum-based chemotherapy, which may be why patients with NSCLC with EGFR mutations have a higher response rate to chemotherapy.

The present study also found that, in NSCLC tissues, mRNA expression levels of ERCCI and RRMI were not correlated $(\mathrm{P}>0.05)$, which is inconsistent with data presented by Reynolds et al (24). The association between the expression of ERCCl and RRM1 mRNA remains controversial and warrants further research. At present, numerous studies have confirmed that therapy can be selected based on patient expression levels of ERCCl and RRMI, and this can be extended to patients with NSCLC $(25,26)$.

In conclusion, the current study has demonstrated that patients with EGFR mutations tend to have lower expression levels of ERCC1 mRNA. We hypothesize that patients with EGFR mutations may be more responsive to cisplatin-based 
chemotherapy, although the molecular mechanisms require further study. No difference in the expression levels of RRMI mRNA was observed between patients with NSCLC with EGFR mutations and those without mutations. In the present study, we have determined the first-line chemotherapy for tumors involving platinum and gemcitabine drug resistance genes and EGFR mutations but not the microtubule drug resistance gene $T U B B 3$ or the thymidylate synthase resistance gene TYMS. Future studies, therefore, are likely to focus on EGFR, TUBB3 and TYMS mutations to better identify effective individualized treatment plans, particularly individualized treatment plans for EGFR-TKI (e.g. imatinib) primary or secondary resistance observed in certain patients.

\section{Acknowledgements}

This study was supported by the Wu Jieping Medical Foundation Clinical Research Special Project Fund (320.6750.1360).

\section{References}

1. Jemal A, Bray F, Center MM, Ferlay J, Ward E and Forman D: Global cancer statistics. CA Cancer J Clin 61: 69-90, 2011.

2. Sher T, Dy GK and Adjei AA: Small cell lung cancer. Mayo Clin Proc 83: 355-367, 2008

3. Cao C, Lu S, Sowa A, et al: Priming with EGFR tyrosine kinase inhibitor and EGF sensitizes ovarian cancer cells to respond to chemotherapeutical drugs. Cancer Lett 266: 249-262, 2008.

4. Herbst RS: Review of epidermal growth factor receptor biology. Int J Radiat Oncol Biol Phys 59 (2 Suppl): 21-26, 2004.

5. Sharma SV, Bell DW, Settleman J and Haber DA: Epidermal growth factor receptor mutations in lung cancer. Nat Rey Cancer 7: 169-181, 2007.

6. Chan SK, Gullick WJ and Hill ME: Mutations of the epidermal growth factor receptor in non-small cell lung cancer - search and destroy. Eur J Cancer 42: 17-23, 2006.

7. Simon GR, Ismail-Khan R and Bepler G: Nuclear excision repair-based personalized therapy for non-small cell lung cancer: from hypothesis to reality. Int J Biochem Cell Biol 39: 1318-1328, 2007.

8. Rosell R, Lord RV, Taron M and Reguart N: DNA repair and cisplatin resistance in non-small-cell lung cancer. Lung Cancer 38: 217-227, 2002.

9. Su C, Zhou S, Zhang L, et al: ERCC1, RRM1 and BRCA1 mRNA expression levels and clinical outcome of advanced non-small cell lung cancer. Med Oncol 28: 1411-1417, 2011.

10. Mok TS, Wu YL, Thongprasert S, et al: Gefitinib or carboplatin-paclitaxel in pulmonary adenocarcinoma. N Engl J Med 361: 947-957, 2009.

11. Olaussen KA, Dunant A, Fouret P, et al: DNA repair by ERCC1 in non-small-cell lung cancer and cisplatin-based adjuvant chemotherapy. N Engl J Med 355: 983-991, 2006.
12. Bepler G, Kusmartseva I, Sharma S, et al: RRM1 modulated in vitro and in vivo efficacy of gemcitabine and platinum in non-small-cell lung cancer. J Clin Oncol 24: 4731-4737, 2006.

13. Lynch TJ, Bell DW, Sordella R, et al: Activating mutations in the epidermal growth factor receptor underlying responsiveness of non-small-cell lung cancer to gefitinib. N Engl J Med 350: 2129-2139, 2004.

14. Paez JG, Jänne PA, Lee JC, et al: EGFR mutations in lung cancer: correlation with clinical response to gefitinib therapy. Science 304: 1497-1500, 2004.

15. Riely GJ, Pao W, Pham D, et al: Clinical course of patients with non-small cell lung cancer and epidermal growth factor receptor exon 19 and exon 21 mutations treated with gefitinib or erlotinib. Clin Cancer Res 12: 839-844, 2006.

16. Kobayashi S, Boggon TJ, Dayaram T, et al: EGFR mutation and resistance of non-small-cell lung cancer to gefitinib. N Engl J Med 352: 786-792, 2005.

17. Ceppi P, Volante M, Novello S, et al: ERCC1 and RRM1 gene expressions but not EGFR are predictive of shorter survival in advanced non-small-cell lung cancer treated with cisplatin and gemcitabine. Ann Oncol 17: 1818-1825, 2006.

18. Cobo M, Isla D, Massuti B, et al: Customizing cisplatin based on quantitative excision repair cross-complementing $1 \mathrm{mRNA}$ expression: a phase III trial in non-small-cell lung cancer. J Clin Oncol 25: 2747-2754, 2007.

19. Pao W, Miller V,Zakowski M, et al: EGF receptor gene mutations are common in lung cancers from 'never smokers' and are associated with sensitivity of tumors to gefitinib and erlotinib. Proc Natl Acad Sci USA 101: 13306-13311, 2004.

20. Deng QH, Qiu Y, Mo MC, et al: EGFR gene copy number, ERCC1 and BRCA1 protein expression and their relationship in non-small cell lung cancer. Zhonghua Zhong Liu Za Zhi 33: 508-512, 2011 (In Chinese).

21. Lin XY, Chen Y and Chen ZZ: Expression of ERCC1 and RRM1 in non-small cell lung cancer (NSCLC) and clinical prognosis. Fujian Yike Daxue Xuebao 45: 10-14, 2011 (In Chinese).

22. Gandara DR, Grimminger P, Mack PC, et al: Association of epidermal growth factor receptor activating mutations with low ERCC1 gene expression in non-small cell lung cancer. J Thorac Oncol 5: 1933-1938, 2010.

23. Mitsudomi T, Morita S, Yatabe Y, et al; West Japan Oncology Group: Gefitinib versus cisplatin plus docetaxel in patients with non-small-cell lung cancer harbouring mutations of the epidermal growth factor receptor (WJTOG3405): an open label, randomised phase 3 trial. Lancet Oncol 11: 121-128, 2010.

24. Reynolds C, Obasaju C, Schell MJ, et al: Randomized phase III trial of gemcitabine-based chemotherapy with in situ RRM1 and ERCC1 protein levels for response prediction in non-small-cell lung cancer. J Clin Oncol 27: 5808-5815, 2009.

25. Simon GR, Schell MJ, Begum M, et al: Preliminary indication of survival benefit from ERCC1 and RRM1-tailored chemotherapy in patients with advanced nonsmall cell lung cancer: evidence from an individual patient analysis. Cancer 118: 2525-2531, 2012.

26. Hu YY, Zhang DB, Dong YG, et al: The protein expression and the significance of RRM1 and ERCC1 in non-small cell lung cancer. Shandong Yi Yao 52: 1-3, 2012 (In Chinese). 